\title{
Adsorption of Mercuric Ions from Aqueous Solution using Activated Carbon and Modified Activated Carbon Prepared from Dried Papyrus Plant
}

\author{
A.M. El-Wakil ${ }^{1}$, W.M. Abou El-Maaty ${ }^{2}$, Ahmed A. Oudah ${ }^{3}$ \\ ${ }^{1,2,3}$ Chemistry Department, Faculty of Science, P.O.Box: 35516, Mansoura University, Mansoura, Egypt
}

\begin{abstract}
It hasprepared several stationary phasesfrom the papyrus plant are of three types. First type: DP phase of dry papyrus, papyrus plant sockedby $0.036 \mathrm{M}(\mathrm{EDTA})$ ethylene diamine tetra-acetic acid at $\mathrm{pH}=10$. Second type: activated carbon $\mathrm{SAC}$ (sulfuric activated carbon) treated by sulfuric acid at ratio 1:3, PAC (phosphoric activated carbon) treated by phosphoric acid at ratio 1:3. Third type: modification activate carbon OSAC (oxidized sulfuric activated carbon) and OPAC (oxidized phosphoric activated carbon) modified by nitric acid at ratio 1:10. The study of effectsfrom different pHvalue (2 - 6), contact time (5 - 180) min, initial concentration $(5$ - 600) $\mathrm{mg} / \mathrm{L}$, temperature $(298$ - 318) $\mathrm{K}$ and adsorbed dosage $(0.025-0.2)$ g.The samples characterized using Scanning Electron Microscope (SEM) and Fourier Transform Infrared (FTIR) Spectrophotometry before and after adsorption.suggesting that the Langmuir isotherm fits better with the experimental data, Langmuir model is much higher than that from Freundlich and the practical adsorption.
\end{abstract}

Keywords: Papyrus plant,Activated carbon,Modified activated carbon, Mercuric ion

\section{Introduction}

Water pollution has become a serious problem nowadays. Both the environment and human beings are exposed to hazards of different pollutants (metal ions, organic pollutants,etc.) from waste and potable water. The enormous damage caused by water pollution have led to numerous investigations having as their object the protection of the threatened environment and living creatures through new methods. Metals such as $\mathrm{Hg}, \mathrm{Pb}$, $\mathrm{Cd}, \mathrm{Cu}$, As,etchave a harmful effect on human physiology and other biological systems. Mercury is generally considered to be one of the most toxic metal found in the environment [1]. Once mercury enters to the food chain, large concentrations of mercury compounds accumulate in human and animals. Mercury has adverse effects on the central nervous system, pulmonary and kidney functions, and causes damages to chromosomes [2, 3]. The tolerance limit for $\mathrm{Hg}$ (II) discharge into inland surface waters is $10 \mu \mathrm{g} / \mathrm{L}$ and in drinking water 1 $\mu \mathrm{g} / \mathrm{L}$. The major sources of mercury pollution in the aquatic environment are chloralkali, pulp paper, oil refining, electrical, rubber processing and fertilizer industries [4]. Various methods have been used to remove mercury from water and wastewater, including chemical precipitation, ion exchange and membrane methods [5]. Activated carbonisone of the important ways which widely used in pollutant removal such as mercury from drinking water. Several studies about the preparation of activated carbon from plants and agricultural residues seeds of have been conducted including coconut shells, groundnut shell, bamboo dust [6], palm kernel shell [7], coir pith [8], wheat husk [9] and rice husk [10]. However there are no reports of obtaining active carbon from papyrus plant by chemical and physical activation methods. The purpose of this study is to investigate removing mercury from aqueous of samples using activated carbon prepared from papyrus plant.Water plant belongs to the Cyprus family. It is sustained plant evergreen growing groups in the edges of ponds. Papyrus breed through division by alrezumat under the surface of the water. It can grows (4 to $5 \mathrm{~m}$ ) (13 to $16 \mathrm{Ft}$ ) high, Papyrus fiber contains 54 $68 \%$ cellulose and $24-32 \%$ lignin.

\section{Experimental}

\section{Material and Method}

\subsection{Instrumental}

1) Water-distillation mega pure 6 liter automatic water still is a compact unit, which designed to provide 6 liter per hour of ultra-high purity distilled water.

2) $\mathrm{pH}$ meter (JENWAY - LTD Instrument, digital model 3310).

3) Spectrophotometer (Apye - Unicom UV100 -Visible Spectrophotometer).

4) Shaker used is: Heidolph Prom ax 2020- Germany. $\mathrm{RPM}=20-400$.

\subsection{Preparation of Stock Mercury Solution}

Add $1 \mathrm{ml}$ of PAR $(0.5 \mathrm{~g} / 250 \mathrm{ml})+10 \mathrm{ml}$ of borate buffer $\mathrm{pH} 9+(0.75,1,2,3,4) \mathrm{ml}$ of metal in $25 \mathrm{ml}$ measuring flask then complete to the mark with distilled water to obtain a final concentration of $(0.75,1,2,3,4)$ ppm and shake well. The maximum Absorbance of the solutions at wavelength $=520 \mathrm{~nm}$ was recorded and construct the standard calibration curve.

\subsection{Preparation of Stationary Phases}

\subsubsection{Dried of Papyrus Plant}

The roots of the papyrus plant was removed while the rest was washed using regular water, next using distilled water last but not least ended up being over loaded throughout $0.036 \mathrm{M}$ (EDTA) on $\mathrm{pH} 10$ instantaneously with regard to eliminating any metal ions adsorbed within the papyrus plant last but not least rinsed using distilled water for a lot of occasions along with dry throughout the oven on $110^{\circ} \mathrm{C}$ with regard to $48 \mathrm{~h}$ next dry (DP) had been floor along with stashed throughout desiccators until finally utilized in adsorption trials. 


\section{International Journal of Science and Research (IJSR) \\ ISSN (Online): 2319-7064}

Index Copernicus Value (2013): 6.14 | Impact Factor (2014): 5.611

\subsubsection{Activated Carbon (Carbonization)}

Activated carbon samples have been prepared in two forms; the first form SAC (sulfuric activated carbon) sample was prepared by soaking $200 \mathrm{~g}$ of dry plant in concentrated sulfuric acid at ratio 1: 3 (wt.: wt.). The second form sample was prepared in a similar way PAC (phosphoric activated carbon) by soaking $75 \mathrm{~g}$ of dried plant in concentrated phosphoric acid at ratio 1: 3 (wt.: wt.), both of the two samples in contact with the acid, at room temperature for 2 days. The two samples separately were treated by distilled water till it becomes free from any traces of $\mathrm{H}_{2} \mathrm{SO}_{4}$ or $\mathrm{H}_{3} \mathrm{PO}_{4}$. The washed 2 samples were dried at $110{ }^{\circ} \mathrm{C}$ for $48 \mathrm{~h}$, in addition to slipped into a muffle oven (in a stainless steel reactor) in which the materials were warmed gradually with absence of fresh air at $550-600{ }^{\circ} \mathrm{C}$ for $4 \mathrm{~h}$. After chilling for you to space temperature, the particular initialized co 2 obtained was rinsed totally together with distilled normal water till the $\mathrm{pH}$ in the supernatant become regular at concerning $(\mathrm{pH}=6)$. After that, the particular materials were dried at $110^{\circ} \mathrm{C}$ for $24 \mathrm{~h}$.

\subsubsection{Modified of Activated Carbon}

The detailed modification process conducted was as follow; first type sample preparation OSAC (oxidized sulfuric activated carbon) by taking15g ofsampleSAC (preparedalready), and add150 mlofconcentrated nitric acid at ratio 1: 10 (wt.: v). The second typeOPAC (oxidized phosphoric activated carbon)samplepreparationby taking20g ofsample PAC (preparedalready), and add $200 \mathrm{ml}$ ofconcentrated nitricacid at ratio 1: 3 (wt.: v). It was boiled for $4 \mathrm{~h}$ to improve the formation regarding functional groups, for instance carboxylic acids. The rest of the product was laundered along with distilled water till the $\mathrm{pH}$ on the supernatant grow to be steady from in relation to $(\mathrm{pH}=6)$. The oxidized $\mathrm{AC}$ turned by utilizing nitric acidity was then dried at $120{ }^{\circ} \mathrm{C}$. Finally. After modification with $\mathrm{HNO}_{3}$, OSAC and OPAC were found to contain some acidic groups, several authors has proposed the formation of new functional groups such as anhydride, hydroxyl and aldehydes, ...., giving a higher cation exchange capacity. The acidic groups increase significantly with the increment of the concentration of nitric acid during the treatment. The carboxylic groups of surface carbon play an important role in the adsorption process [11].

\section{Adsorption Study}

Metal solutions with initial concentration of (10 - 600) $\mathrm{mg} / \mathrm{L}$ were prepared, and $0.025 \mathrm{~g}$ of adsorbent was added to the solutions in a $25 \mathrm{ml}$ bottle flask. All the adsorption operations were prepared at $\mathrm{pH}$ value 5 . This was followed by agitating the solution on a rotary shaker with the speed of $150 \mathrm{rpm}$ After $5 \mathrm{~h}$. Concentration of heavy metal solution was adsorbent by using (OSAC, OPAC, PAC, SAC and DP). Different dosages of adsorbent were added to $\mathrm{Hg}^{2+}$ solution. The amount of adsorbent used was $0.025,0.075,0.1,0.15$ and $0.2 \mathrm{~g}$, at temperature range of 298 to $318 \mathrm{~K}$. pH effect on the adsorption of $\mathrm{Hg}^{2+}$ was studied by varying the $\mathrm{pH}$ from 1.0 to 6.0 . The samples were withdrawn from the shaker at predetermined time $(5-180)$ minute intervals. The amounts of metal ion removed by sorbents qe and percent extracted \% E can be calculated using the following equations:

$$
\begin{gathered}
\mathbf{\%} \mathbf{E}=\frac{\left(C_{0}-C_{e}\right)}{C_{0}} \times \mathbf{1 0 0} \\
\mathbf{q}_{\mathbf{e}}=\frac{\left(C_{0}-C_{e}\right) V}{m}
\end{gathered}
$$

\section{Result and Discussion}

\section{Characterization of Stationary Phases}

\subsection{FTIR Spectroscopy}

FTIR spectra had been documented between four thousand and $100 \mathrm{~cm}^{-1}$ employing a Mattson four thousand FTIR spectrometer. Discs had been served by first combining $1 \mathrm{mg}$ dried up carbon trial together with $500 \mathrm{mg}$ regarding $\mathrm{KBr}$ (Merck pertaining to spectroscopy) within the agate mortar then pressing resulting mixture with 5 tone $/ \mathrm{cm}^{2}$ pertaining to 5 minutes and 10 tone $/ \mathrm{cm}^{2}$ pertaining to 5 min below vacuum. 


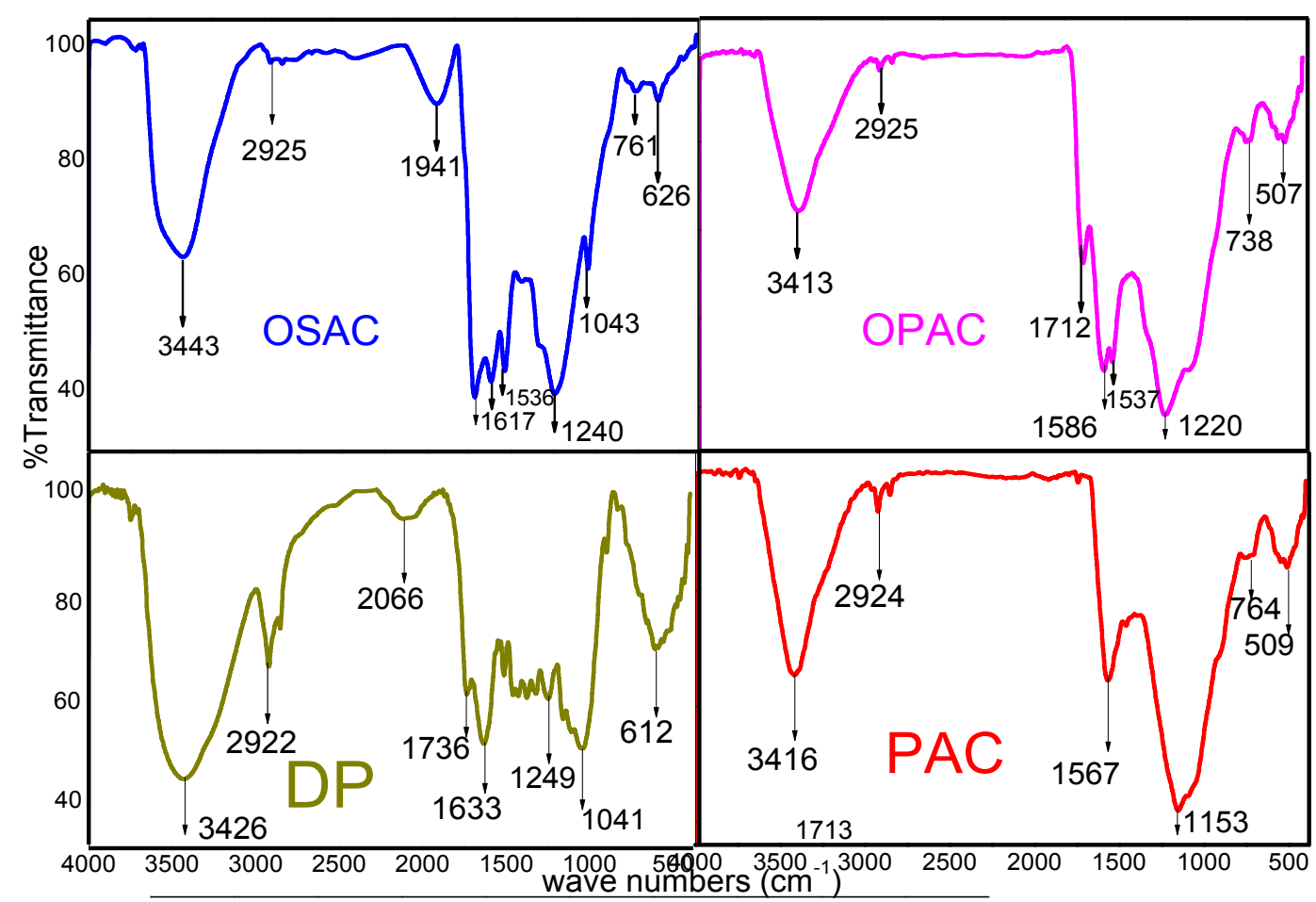

Figure 1: FTIR spectrum of oxidized activated carbon (OSAC, OPAC), activated Carbon (PAC) and dried (DP) papyrus plant

\begin{tabular}{|c|c|}
\hline Function group & Wave Number $\left(\mathrm{Cm}^{-1}\right)$ \\
\hline $\begin{array}{c}\text { O-H stretching mode of } \\
\text { hexagonal group }\end{array}$ & $(3413-3443) \mathrm{cm}^{-1}$ \\
\hline Aliphatic (C-H ) & $(2922-2925) \mathrm{cm}^{-1}$ \\
\hline $\mathrm{C}=\mathrm{C}$ stretching in aromatic ring & Bonds near $(1633-1500) \mathrm{cm}^{-1}$ \\
\hline $\begin{array}{c}\text { C-O bonds such as those in } \\
\text { ethers, phenols, and esters }\end{array}$ & $(1300-1000) \mathrm{cm}^{-1}$ \\
\hline $\begin{array}{c}\text { Highly conjugated }(\mathrm{C}=\mathrm{O} \\
\text { stretching, C-O stretching in } \\
\text { carboxylic groups and carboxylic } \\
\text { moieties. }\end{array}$ & Bonds near $(1220-1240) \mathrm{cm}^{-1}$ \\
\hline $\begin{array}{c}\text { (C=O) stretching vibrations of } \\
\text { carboxyl groups saturated about } \\
\text { OSAC and OPAC. }\end{array}$ & Band at $\left(1712\right.$ and 1713) $\mathrm{cm}^{-1}$ \\
\hline
\end{tabular}

\subsection{Scanning Electron Microscopy (SEM)}

Scanning electron microscopy of OSAC, OPAC, PAC, SAC and DP were obtained prior to the analysis, the samples were dried at $110^{\circ} \mathrm{C}$ for $4 \mathrm{~h}$. Using scanning electron microscope (SEM; JSM, model 6510). The edges of the double-sided tape were printed with gold. Micrographs were obtained in a secondary electron imaging mode using a potential difference of $30 \mathrm{KV}$. The micrographs obtained plainly reveal the actual porous composition connected with unique adsorbents from magnification of $\mathrm{x} 1500$ and $\mathrm{x} 500$ for (OSAC, OPAC, $\mathrm{PAC}$ and DP), respectively. 


\section{International Journal of Science and Research (IJSR) \\ ISSN (Online): 2319-7064}

Index Copernicus Value (2013): 6.14 | Impact Factor (2014): 5.611
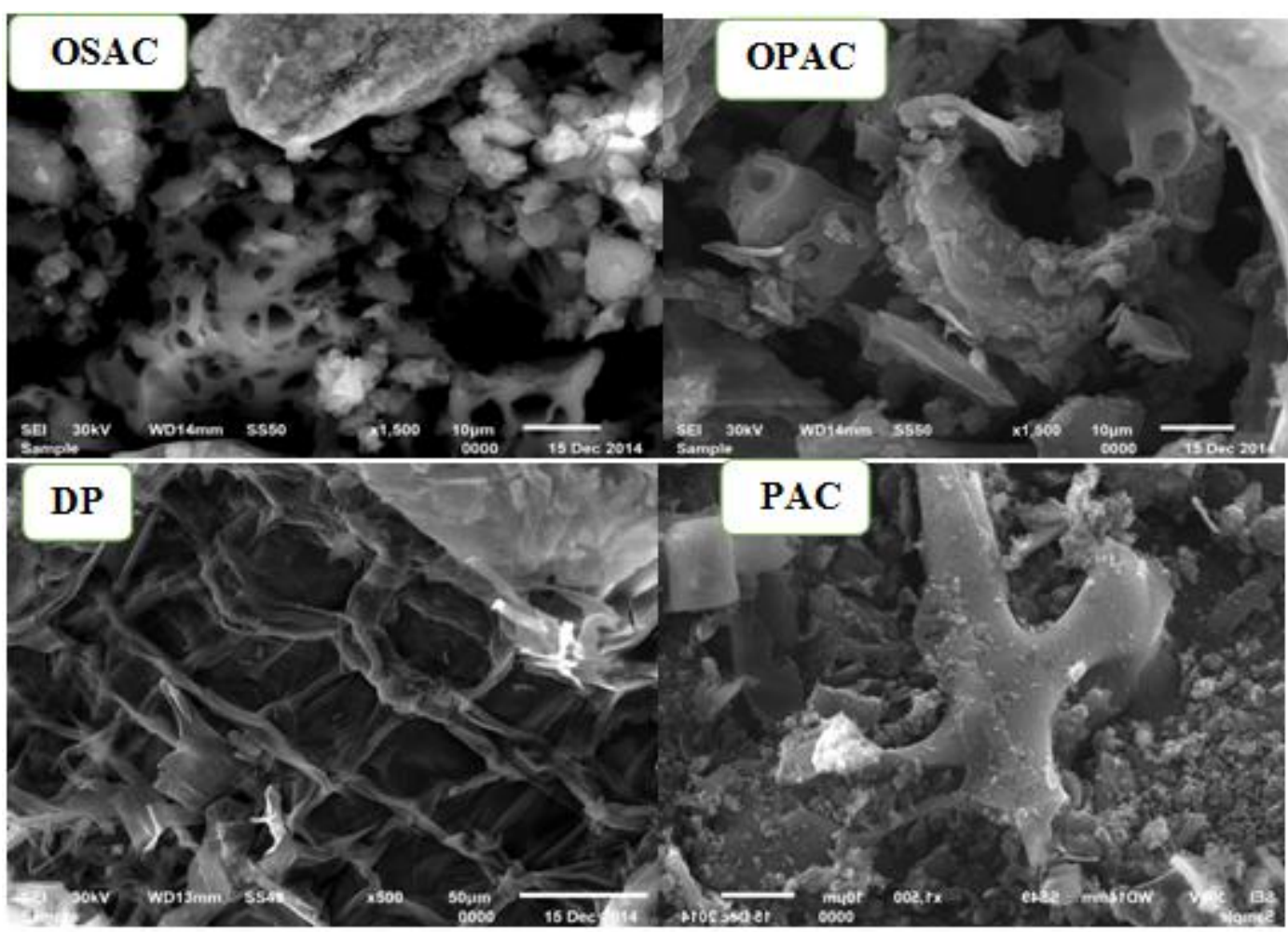

Figure 2: SEM photographs of OSAC, OPAC, PAC and DP.

\section{Studying the Effects on $\mathrm{Hg}^{2+}$ ions}

\subsection{The impact of $\mathrm{pH}$ on $\mathrm{Hg}^{2+}$ Adsorption}

Solution's pH is an important factor that affects the bio-sorption of metal ions. In order to make a study how this factor has an impact on sorption of mercury by OSAC, OPAC, PAC and DP $\mathrm{pH}$ was changed from $1-6$ as illustrated in Figure (3). There were relatled experiments with initial metal concentration reached $50 \mathrm{mg} / \mathrm{L}$ and biomass concentration $1 \mathrm{~g} /$ Lat room temperature. Once there is an increase in the $\mathrm{pH}$ from $\mathrm{pH}=1-6$, the adsorbed quantity of $\mathrm{Hg}^{2+}$ at equilibrium $\left(\mathrm{q}_{\mathrm{e}}\right)$ rises (19.47 $23.68) \mathrm{mg} / \mathrm{g},(16.95-23.68) \mathrm{mg} / \mathrm{g},(14.97-20) \mathrm{mg} / \mathrm{g}$ and $(9.64$ - 16.66) $\mathrm{mg} / \mathrm{g}$ respectively. The highest efficacy of bio-sorption was detected at $\mathrm{pH}$ of 6 . Actually, the adsorption dependency of $\mathrm{pH}$ of aqueous mercury could be defined by two mechanisms.

1. First mechanism: the effect of $\mathrm{pH}$ on separation of acidic and basic surface practical groups in addition to the impact on species of mercury. It is stated that the most governing mercury species at $\mathrm{pH}<3$ and $\mathrm{pH}>5$ are $\mathrm{Hg}^{2+}$ and $\mathrm{Hg}(\mathrm{OH})_{2}$, respectively [12]. In aqueous solutions and $\mathrm{pH}$ between (4 and 6), $\mathrm{Hg}\left(\mathrm{Cl}_{2}\right)_{2}, \mathrm{Hg}(\mathrm{Cl})^{+}, \mathrm{HgCl}, \mathrm{Hg}(\mathrm{OH})^{+}$, can form these cationic complexes. With $\mathrm{pH}$ values of other solution, the surface in control of activated carbon could possibly change because of the surface hydroxylation or protonation of functional groups. Therefore, different mercury species with different charges can bind to the sites of adsorption on the activated carbon at every $\mathrm{pH}$ of the solution. In particular, at low $\mathrm{pH}$ values, the activated carbon surface is charged in a positive way which has an opposing effect on the mercury cations adsorption such as $\mathrm{Hg}^{2+}$, $\mathrm{Hg}(\mathrm{Cl})^{+}$and $\mathrm{Hg}(\mathrm{OH})^{+}[13]$.

2. Second Mechanism: The mercury species and protons competition in order to bound on the activated carbon's sites of adsorption at low pH sums [14]. Actually, the attentiveness of
$\mathrm{H}^{+}$is sufficient to contest with species of mercury which to be adsorbed in the $\mathrm{AC}$ when at very low $\mathrm{pH}$ amounts. When $\mathrm{pH}$ increases, the density of adverse charge on the surface of adsorbent rises also due to the active sites deprotonation, thus the attitude of ions with positive charge appearance at $\mathrm{pH}$ values $(\mathrm{pH}>5)$, mercury's solubility declines owing to the wide-ranging hydrolysis (the ratio of $\mathrm{HgClOH}$ and $\mathrm{Hg}(\mathrm{OH})_{2}$ species rises) consequently, in order to get rid of $\mathrm{Hg}$ (II) ions precipitation, altogether the following experiments were carried out at $\mathrm{pH}=5.0$.

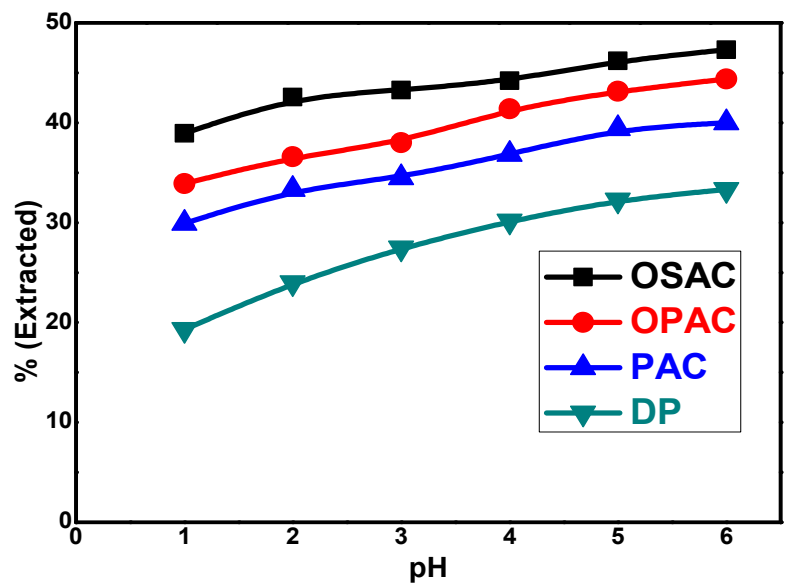

Figure 3: Effect of the $\mathrm{pH}$ values on adsorption capacity of $\mathrm{Hg}^{2+}$ by OSAC, OPAC, PAC and DP (Conditions: $\mathrm{C}_{\mathrm{o}}$ $=50 \mathrm{mg} / \mathrm{L}, \mathrm{T}=25^{\circ} \mathrm{C}$, adsorbent dose $=0.025 \mathrm{~g}, \mathrm{~V}=25$ $\mathrm{ml})$.

\subsection{The Contact Time on Adsorption}

The relation concerning time of contact and sorption of $\mathrm{Hg}$ (II) onto OSAC, OPAC, PAC and DP at initial concentration of $\mathrm{Hg}$ (II) (250 ppm) (DP), $400 \mathrm{ppm}$

\section{Volume 4 Issue 11, November 2015}




\section{International Journal of Science and Research (IJSR) \\ ISSN (Online): 2319-7064 \\ Index Copernicus Value (2013): 6.14 | Impact Factor (2014): 5.611}

(PAC) and 500 ppm (OSAC, OPAC) is illustrated in figure (4). Results of the study showed that sorbate species up taking was rapid at initial time by the time of contact and a big portion of the entire quantities of metal were extracted rapidly through few minutes, more than $63 \%, 61 \%, 59 \%$ and $48 \%$ of the adsorption capacities consistent with adsorbents for $\mathrm{Hg}$ (II) happened through $5 \mathrm{~min}$ for OSAC, OPAC, PAC and DP, correspondingly. Then, it declines close to the equilibrium and the extreme getting rid of mercury (II) happened through 60 90 minutes (OSAC, OPAC, and PAC) and 45-60 minutes (DP) the sorption rate is almost constant at this time. This is clear by the rule that huge vacant sites of surface are available for sorption during the initial phase, and after no few seconds, the remaining vacant surface sites are hard to be involved because of the repulsion forces between the ions of solute on the solid and the main phases. Next 90 min (OSAC, OPAC, and PAC) and $60 \mathrm{~min}$ (DP), the uptake was nearly constant to an extent that it may be reaching time of equilibrium of the adsorption of $\mathrm{Hg}$ (II). To be sure that there was an adequate contact time, experiments of additional adsorption were done for $7 \mathrm{~h}$.

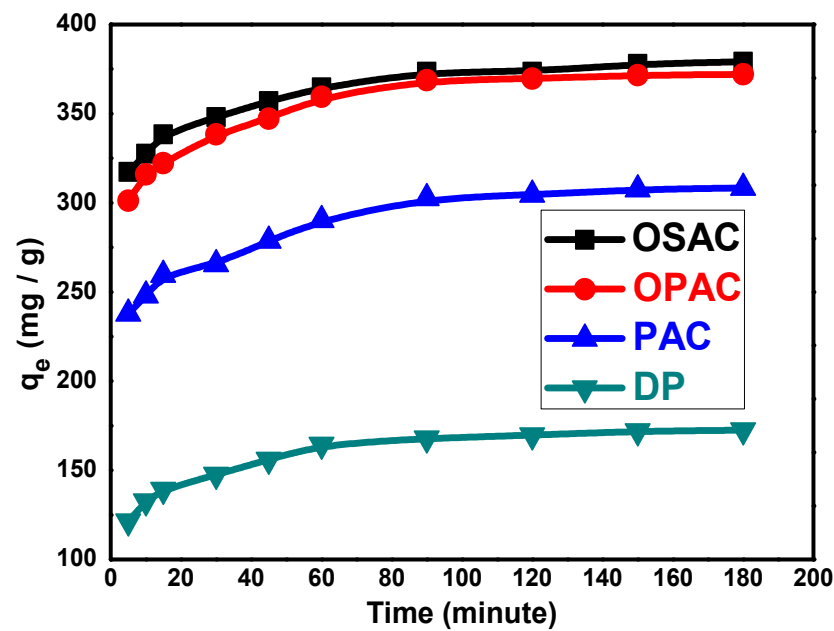

Figure 4: Effect of contact time on adsorption capacity of $\mathrm{Hg}^{2+}$ by OSAC, OPAC, PAC and DP. (Conditions: $\mathrm{C}_{\mathrm{o}}=250 \mathrm{ppm}$ (DP), $400 \mathrm{ppm}(\mathrm{PAC})$ and $500 \mathrm{ppm}(\mathrm{OSAC}, \mathrm{OPAC}), \mathrm{T}=25^{\circ} \mathrm{C}$, adsorbent dose $=0.25 \mathrm{~g}, \mathrm{~V}=250 \mathrm{ml})$.

\subsection{The effect of initial concentration on $\mathrm{Hg}^{2+}$ up taking:}

The impact of initial concentration of $\mathrm{Hg}$ (II) on the uptake capacity equilibrium is illustrated in Figure (5). Figure presents clearly that on increasing the initial concentration of $\mathrm{Hg}$ (II) to $(10$ - 600) $\mathrm{mg} / \mathrm{L}$ (OSAC, OPAC) , (10 - 400) mg/L (PAC) and (10 - 300) $\mathrm{mg} / \mathrm{L}$ (DP) at $25^{\circ} \mathrm{C}$, the $\mathrm{Hg}$ (II) quantity adsorbed at equilibrium (qe) increases as well $(9.12-240.35) \mathrm{mg} / \mathrm{g},(8.94$ - 199.7) $\mathrm{mg} / \mathrm{g},(8.83-115.14) \mathrm{mg} / \mathrm{g}$ and $(8.12-75.53) \mathrm{mg} / \mathrm{g}$ for OSC, OPC, PAC and DP correspondingly. Seemingly, the initial concentration of $\mathrm{Hg}$ (II) affecting strongly the $\mathrm{Hg}$ (II) capacity, to be adsorbed on variable adsorbents. The adsorbed quantity of $\mathrm{Hg}$ (II) onto OSAC, OPAC, PAC and DP increases as the initial $\mathrm{Hg}$ (II) concentration increases at a constant quantity of adsorbent. This might be because of the fact that, the greater concentration of $\mathrm{Hg}$ (II) is, the more powerful the energetic force of the concentration gradient, and thus the higher the capacity of adsorption. The $\mathrm{C}_{\mathrm{o}}$ affords the essential driving force to overcome the resistances to the bulk transfer of $\mathrm{Hg}$ (II) between the aqueous and the solid phases. The increasing of $\mathrm{C}_{\mathrm{o}}$ similarly rises the interaction between $\mathrm{Hg}$ (II) and OSAC, OPAC, PAC and DP adsorbents. Consequently, the increasing of $\mathrm{C}_{\mathrm{o}}$ of $\mathrm{Hg}$

(II) rises the $\mathrm{Hg}$ (II).adsorption uptake.

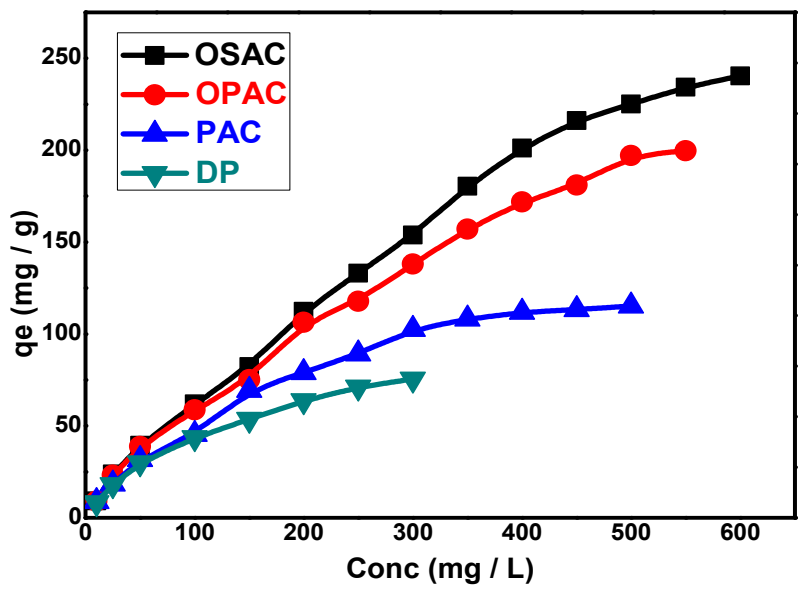

Figure 5: Effect of initial metal concentration on the removal of $\mathrm{Hg}^{2}$. (Conditions: $\mathrm{C}_{\mathrm{o}}=(10-600) \mathrm{mg} / \mathrm{L}$ OSAC, OPAC, $(10-400) \mathrm{mg} / \mathrm{L}$ PAC and $(10-300) \mathrm{mg} / \mathrm{L}$ $\mathrm{DP}, \mathrm{T}=25^{\circ} \mathrm{C}$, adsorbent dose $=0.025 \mathrm{~g}, \mathrm{~V}=25 \mathrm{ml}$ ).

\subsection{The dosage of adsorbent}

The dosage of bio-sorbent effect on the $\mathrm{Hg}$ (II) extracted is illustrated in figure (6). This figure shows that the $\mathrm{Hg}$ (II) extracted ratio grows thru the growth in dosage of bio-sorbent $(0.025$ - 0.2) gm PAC, DP and (0.025 - 0.1) g OSAC, OPAC. The percentage of extracted mercury by OSAC, OPAC, PAC and DP increases (41.52 - 50.29) \%, (37.42 - 47.66) \%, (38.59 - 66) \% and (16.95 - 51.81) \% correspondingly. There is not a noteworthy rise in extracted of $\mathrm{Hg}$ (II) when dosage of bio-sorbent rises more than $0.2 \mathrm{gm}$ (PAC, DP) and $0.1 \mathrm{gm}$ (OSAC, OPAC), which proposes that the highest bio-sorption is reached after a definite dosage of bio-sorbent, and henceforth the ions amount stays unchanged even with extra increase in the area surface of the bio-sorbent, that in sequence makes the binding sites number higher. Nevertheless, at high dosages sorbent, the ions of metal available are not adequate to all the exchange sites on the bio-sorbent, which causes metal uptake decreasing [15]. Thus, the best dosage for dried papyrus plant and activated carbon improved is ranged from 0.2 to $0.1 \mathrm{gm}$ but $1 \mathrm{gm}$ dosage is utilized for all additional experiments. 

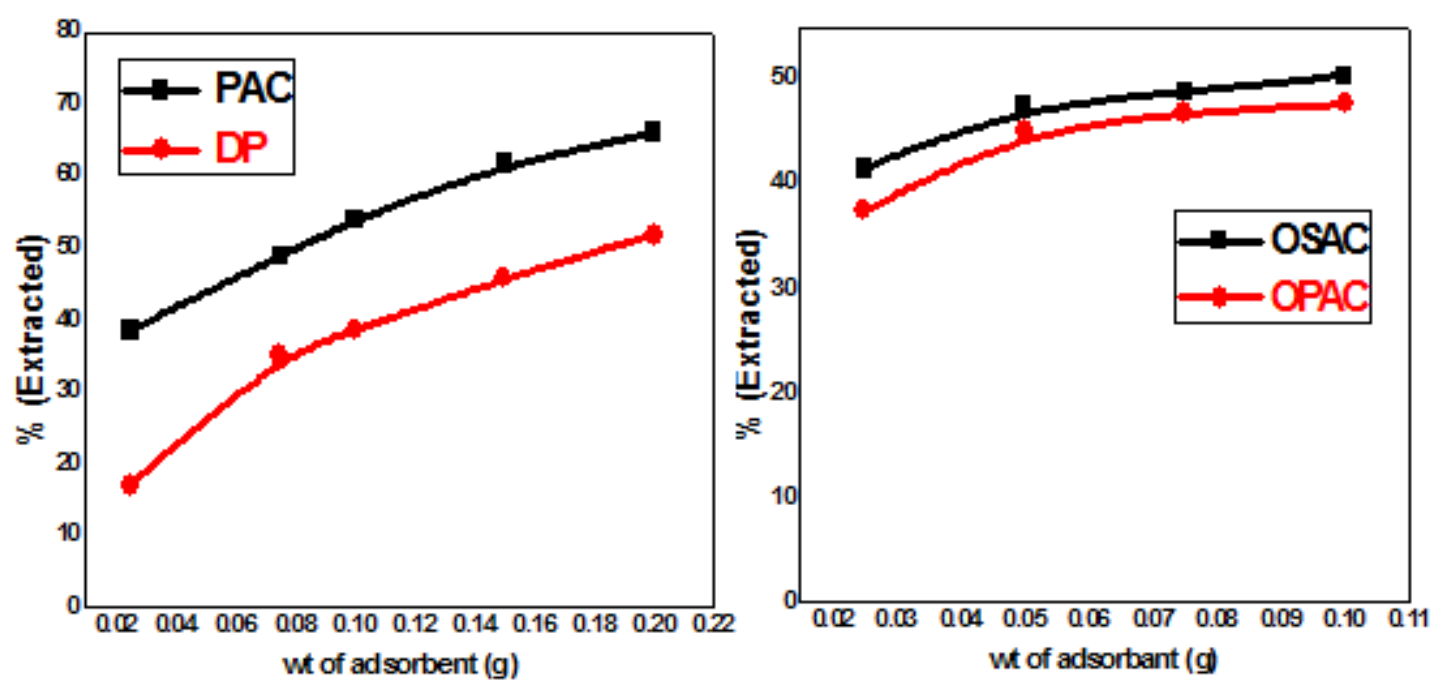

Figure 6: Effect of sorbent dosage on the removal of $\mathrm{Hg}^{2+}$. (Conditions: $\mathrm{T}=25^{\circ} \mathrm{C}, \mathrm{C}_{\mathrm{o}}=250 \mathrm{ppm}(\mathrm{DP}), 400 \mathrm{ppm}(\mathrm{PAC})$ and $500 \mathrm{ppm}(\mathrm{OSAC}, \mathrm{OPAC}), \mathrm{V}=25 \mathrm{ml}$, time $=6 \mathrm{~h}, \mathrm{pH}=5)$.

\subsection{The Temperature on Adsorption of Mercury}

In order to study the temperature's impact on adsorption of mercury by adsorbents of OSAC, OPAC, PAC, and DP, experiment was carried out at different temperature rates, ranged between $25^{\circ} \mathrm{C}$ and $45{ }^{\circ} \mathrm{C}$ (see Figure 7). Initial concentration range $(10-600 \mathrm{mg} / \mathrm{L})$ and biomass concentration of $1 \mathrm{~g} / \mathrm{L} \mathrm{pH} 5.0$ were, used in the conducted experiments. From table 9 , we can see that, as there was an increase in temperature from $25^{\circ} \mathrm{C}$ to $45{ }^{\circ} \mathrm{C}$, the highest capacities of $\mathrm{Hg}^{2+}$ adsorption eliminated by OSAC, OPAC, PAC and DP clearly increased $(240.35-329.23) \mathrm{mg} / \mathrm{g},(199.7-292.69) \mathrm{mg} / \mathrm{g},(115.14-$ $230.99) \mathrm{mg} / \mathrm{g}$ and $(75.53-140.93) \mathrm{mg} / \mathrm{g}$, correspondingly. In actual fact, there are two main effects of the temperature on the processes of porous adsorbents adsorption. It could have an impact on the rate of diffusion of the sorbate within the pores resulting from the decreasing viscosity of solution and the number of the sites of sorption which are produced due to the internal bonds breaking close to the edge of active surface sites of sorbent, this helps improve the capacity of adsorption of the adsorbents [16]. The results show that the adsorption response of $\mathrm{Hg}$ (II) ions adsorbed by OSAC, OPAC, PAC and DP adsorbents are higher as increasing of the temperature, which indicates that the process is endothermic. The greater rates in removal of mercury with higher temperature may be due to the chemical interactions that elevated between mercury ions and the efficient groups on the surface of the activated carbon, which shows that the process is chemisorption. In other words, the higher rates of temperature can increase the diffusion rate of $\mathrm{Hg}$ (II) ions and the number of sorption sites, and thus elevates the adsorption capability of prepared activated carbon. By noticing the attained results, it is clear that the adsorption of the mercury rises in the direction of OSAC $>$ OPAC $>$ PAC $>$ DP under all the studied conditions like temperature, concentration, and $\mathrm{p} \mathrm{H}$. The reason of this behavior refers to the increasing in the adsorbent surface area and the increasing of the number of active sites (efficient groups) on the adsorbents' surface.

Table 1: Effect of temperature on maximum adsorption capacities of $\mathrm{Hg}^{2+}$ by OSAC, OPAC, PAC and DP.

\begin{tabular}{|c|c|c|c|}
\hline \multirow{2}{*}{ Sample } & \multicolumn{3}{|c|}{ Qe $(\mathrm{mg} / \mathrm{g})$} \\
\cline { 2 - 4 } & $25^{\circ} \mathrm{C}$ & $35^{\circ} \mathrm{C}$ & $45^{\circ} \mathrm{C}$ \\
\hline OSAC & 240.350 & 322.222 & 329.239 \\
\hline OPAC & 199.707 & 264.035 & 292.690 \\
\hline PAC & 115.146 & 166.666 & 230.994 \\
\hline DP & 75.532 & 122.807 & 140.935 \\
\hline
\end{tabular}




\section{International Journal of Science and Research (IJSR) \\ ISSN (Online): 2319-7064}

Index Copernicus Value (2013): 6.14 | Impact Factor (2014): 5.611
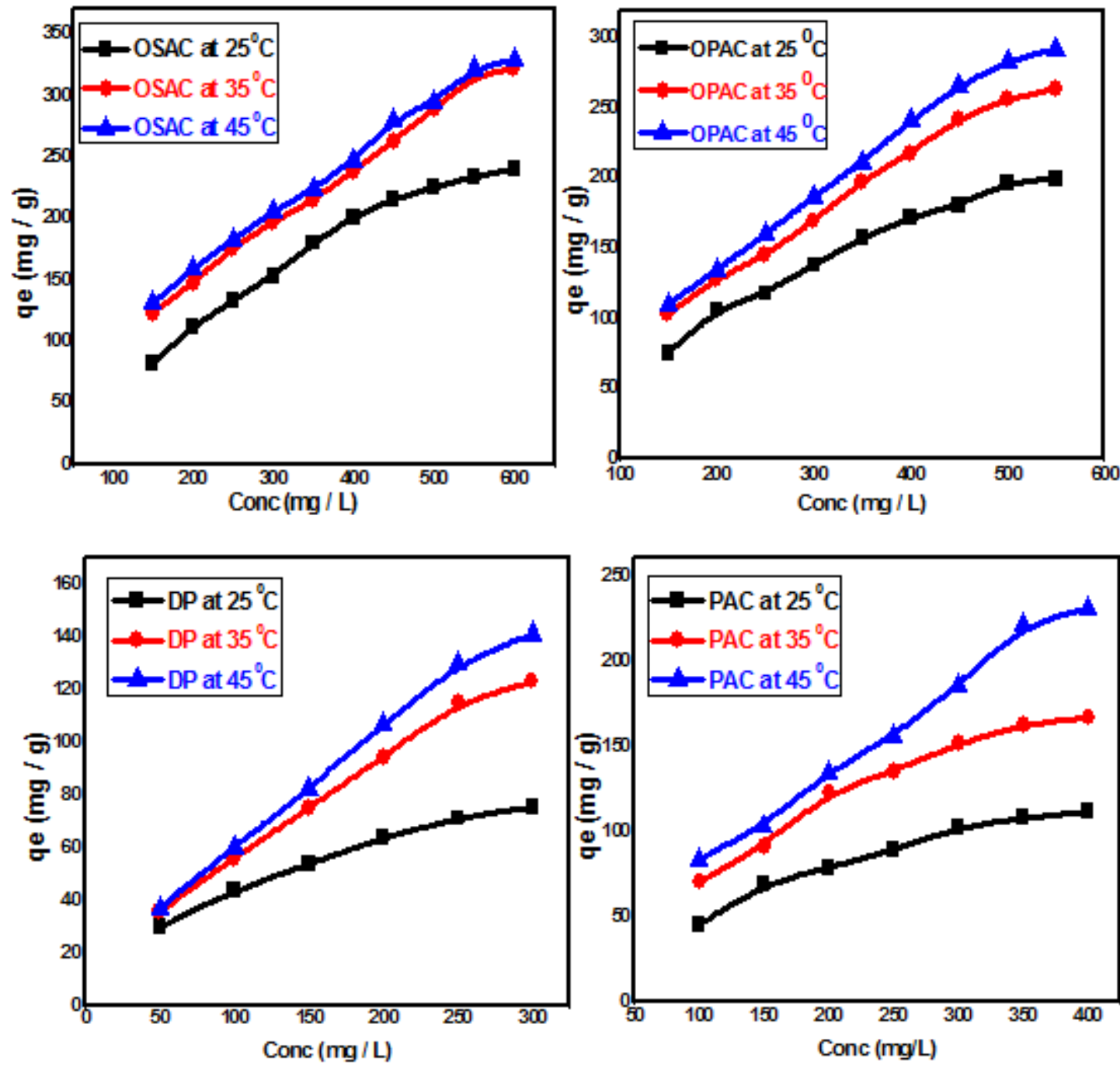

Figure 7: Effect of temperature on adsorption capacity of $\mathrm{Hg}^{2+}$ by OSAC, OPAC, PAC and DP. (Conditions: $\mathrm{C}_{\mathrm{o}}=10-600$ ppm, adsorbent dose $=0.025 \mathrm{~g}, \mathrm{~V}=25 \mathrm{ml}, \mathrm{pH}=5$ ).

\section{Adsorption Isotherms}

The experimental adsorption equilibrium data were analysed according to Langmuir and Freundlich isotherm models which can be calculated as follows:

Freundlich isotherm: $\ln \mathrm{q}_{\mathrm{e}}=\ln \mathrm{K}_{\mathrm{f}}+\frac{1}{n} \ln \mathrm{C}_{\mathrm{e}}$ (3)

$$
\text { Langmuir isotherm: } \frac{\mathrm{C}_{\mathrm{e}}}{\mathrm{q}_{\mathrm{e}}}=\frac{1}{\mathrm{Qb}}+\frac{\mathrm{C}_{\mathrm{e}}}{\mathrm{Q}}(3)
$$

As $\mathrm{q}_{\mathrm{e}}$ is the adsorbed amount at equilibrium $(\mathrm{mg} / \mathrm{g}), \mathrm{Ce}$ is the equilibrium of the $\mathrm{Hg}^{2+}(\mathrm{mg} / \mathrm{L})$ concentration, constant $\mathrm{b}$ is linked to the adsorption energy ( $\mathrm{L} / \mathrm{mg}), \mathrm{Q}$ is the adsorption capacity of Langmuir monolayer $(\mathrm{mg} / \mathrm{g}), \mathrm{K}_{\mathrm{f}}$ is approximately index for the adsorption capacity, and $1 / \mathrm{n}$ is the adsorption intensity. Langmuir and Freundlich isotherms for adsorption of $\mathrm{Hg}^{2+}$ onto OSAC, OPAC, PAC and DP at different initial concentrations are presented in figures $(8,9)$, correspondingly. Tables $(2,3)$ have a summarized review on the constants of Langmuir and Freundlich, and the determined coefficients. Obviously, the coefficient of regression $\mathrm{R}^{2}$ that obttained from Langmuir model has higher rates than that obtained from model of Freundlich, suggesting that the Langmuir isotherm is more fit thru experimental data. Capacity monolayer adsorption $\left(\mathrm{Q}_{\max }\right)$ of $\mathrm{Hg}^{2+}$ was the highest by OSAC, OPAC, PAC and DP at 25 ${ }^{\circ} \mathrm{C}$ and was found to be with (240.35) $\mathrm{mg} / \mathrm{g}$, (199.7) $\mathrm{mg} / \mathrm{g}$, (115.14) $\mathrm{mg} / \mathrm{g}$ and (75.53) $\mathrm{mg} / \mathrm{g}$ are all identical in the experimental data. Necessary features of the Langmuir isotherm can also be expressed in terms of a nondimensional constant separation factor or equilibrium parameters, $R_{L}$, which is defined as follows:

$$
\mathbf{R}_{\mathrm{L}}=\frac{1}{1+\mathrm{bC}_{0}} \text { (4) }
$$

Where $b(\mathrm{~L} / \mathrm{mg})$ is the Langmuir constant and $\mathrm{C}_{\mathrm{o}}(\mathrm{mg} / \mathrm{L})$ is the initial concentration in the liquid phase. The value of $R_{L}$ indicates the figure of the isotherm to be either unfavorable $\left(R_{L}>1\right)$, linear $\left(R_{L}=1\right)$, or favorable $(0<$ $\left.\mathrm{R}_{\mathrm{L}}<1\right)$ or irreversible $\left(\mathrm{R}_{\mathrm{L}}=0\right)$. For Hg (II) adsorption on OSAC, OPAC, PAC and DP, $\mathrm{R}_{\mathrm{L}}$, the attained values are ranged between zero and 1 , thus ensuring that the adsorption is a advantageous procedure. 


\section{International Journal of Science and Research (IJSR) \\ ISSN (Online): 2319-7064}

Index Copernicus Value (2013): 6.14 | Impact Factor (2014): 5.611
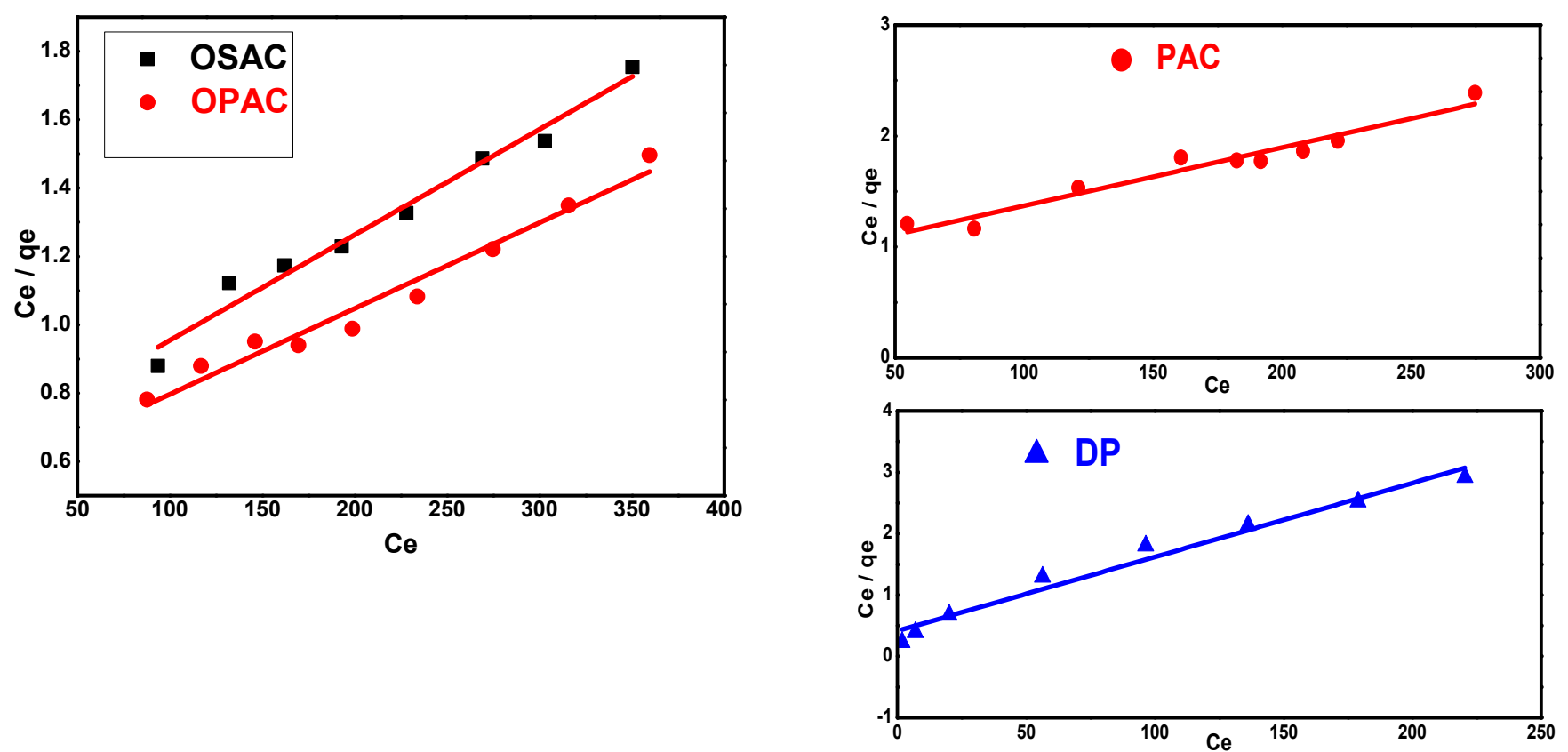

Figure 8: Langmuir plot for the adsorption of $\mathrm{Hg}^{2+}$ by OSAC, OPAC, PAC and DP.

Table 2: Parameters of Langmuir isotherm for adsorption of $\mathrm{Hg}^{2+}$ by OSAC, OPAC, PAC and DP

\begin{tabular}{|c|c|c|c|c|c|}
\hline \multirow{2}{*}{ Adsorbents } & \multicolumn{5}{|c|}{ Langmuir parameters } \\
\cline { 2 - 6 } & $\mathrm{R}^{2}$ & $\mathrm{Q}_{\text {expr }}$ & $\mathrm{Q}_{\max , \text { fitted }}$ & $\begin{array}{c}\mathrm{b} \\
(\mathrm{mg} / \mathrm{L})\end{array}$ & $\mathrm{R}_{\mathrm{L}}$ \\
\hline OSAC & 0.973 & 240.350 & 333.333 & 0.004 & 0.263 \\
\hline OPAC & 0.967 & 199.707 & 400.000 & 0.004 & 0.284 \\
\hline PAC & 0.942 & 115.146 & 200.000 & 0.005 & 0.302 \\
\hline DP & 0.970 & 75.532 & 83.333 & 0.028 & 0.104 \\
\hline
\end{tabular}
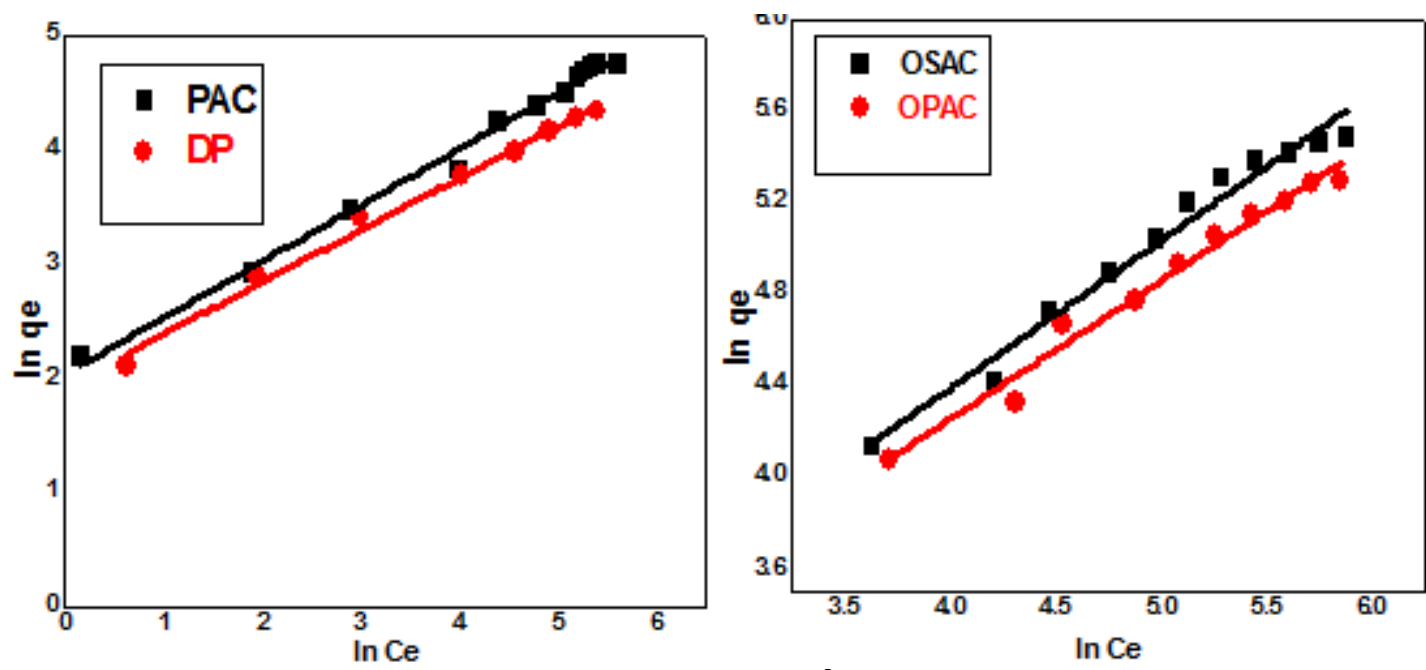

Figure 9: Freundlich plot for the adsorption of $\mathrm{Hg}^{2+}$ by OSAC, OPAC, PAC and DP

Table 3: Parameters of Freundlich isotherm for adsorption of

\begin{tabular}{|c|l|l|c|}
\hline \multirow{2}{*}{$\mathrm{Hg}^{2+}$ by OSAC, OPAC, PAC and DP } \\
\hline \multirow{2}{*}{ Adsorbents } & \multicolumn{3}{|l|}{ Freundlich parameters } \\
\cline { 2 - 4 } & $\mathrm{R}^{2}$ & $\mathrm{~K}_{\mathrm{f}}$ & $1 / \mathrm{n}$ \\
\hline OSAC & 0.973 & 6.002 & 0.646 \\
\hline OPAC & 0.976 & 6.190 & 0.605 \\
\hline PAC & 0.991 & 7.610 & 0.491 \\
\hline DP & 0.990 & 6.840 & 0.454 \\
\hline
\end{tabular}

\section{Adsorption Kinetics}

In order to make a study on the adsorption process steps mechanism, like the transport of mass and chemical reaction procedures, kinetic models were utilized in testing the experiment data. The adsorption kinetics of $\mathrm{Hg}^{2+}$ on the revised papyrus plant activated carbon and dried papyrus plant were analysed using pseudo-firstorder, pseudo-second-order, and intra-particle diffusion 


\section{International Journal of Science and Research (IJSR) \\ ISSN (Online): 2319-7064 \\ Index Copernicus Value (2013): 6.14 | Impact Factor (2014): 5.611}

models. The pseudo-first-order kinetic model can calculated as following:

$$
\log \left(\mathbf{q}_{\mathrm{e}}-\mathbf{q}_{\mathrm{t}}\right)=\log \mathbf{q}_{\mathrm{e}}-\frac{K_{1} t}{2.303}
$$

Where qe and qt are the quantities of mercury adsorbed $(\mathrm{mg} / \mathrm{g})$ on equilibrium and at time $\mathrm{t}$ (minutes), correspondingly, and $\mathrm{k}_{1}$ is a constant adsorption rate $\left(\mathrm{min}^{-1}\right)$. $\mathrm{k}_{1}$ values were dtermined from the curves of $\ln (\mathrm{qe}-\mathrm{qt}$ ) versus $\mathrm{t}$ (min) (figure 10) at mercury initial concentration of $250 \mathrm{ppm}$. Values of connection coefficient $\mathrm{R}^{2}$ are low, the experimental qe values do not contest with those calculated, obtained from the linear curves Table (4). This indicates that adsorption of cadmium on OSAC, OPAC, PAC and DP is not a first-order reaction. The secondorder kinetic model is stated as:

$$
\frac{t}{q_{t}}=\frac{1}{K_{2} q_{e}^{2}}+\frac{t}{q_{e}}
$$

$\mathrm{k}_{2}$ is second-order adsorption rate constant $\left(\mathrm{g} \mathrm{mg}^{-1} \mathrm{~min}^{-1}\right)$. If the second-order kinetics is relevant, the curve of $\mathrm{t} / \mathrm{q} 1$ versus $t$ must display a linear relation. Values of $k_{2}$ and qe were determined from the intercept and slope of the curves of $t / q_{t}$ versus $t$. Linear curves of $t / q_{t}$ versus $t$ figure (11) demonstrate a good match between experimental and calculated $\mathrm{q}_{\mathrm{e}}$ values as shown inTable (5). The coefficients of connection for the second-order kinetic model are greater than 0.999 demonstrating that the system of adsorption can be described better using the model of pseudo second kinetic. Furthermore, the adsorption capacities calculated using pseudo-secondorder plots are convenient with the experimental values. This endorses the previous suggestion, that the mercury adsorption by OSAC, OPAC, PAC and DP is controlled by chemisorption process.
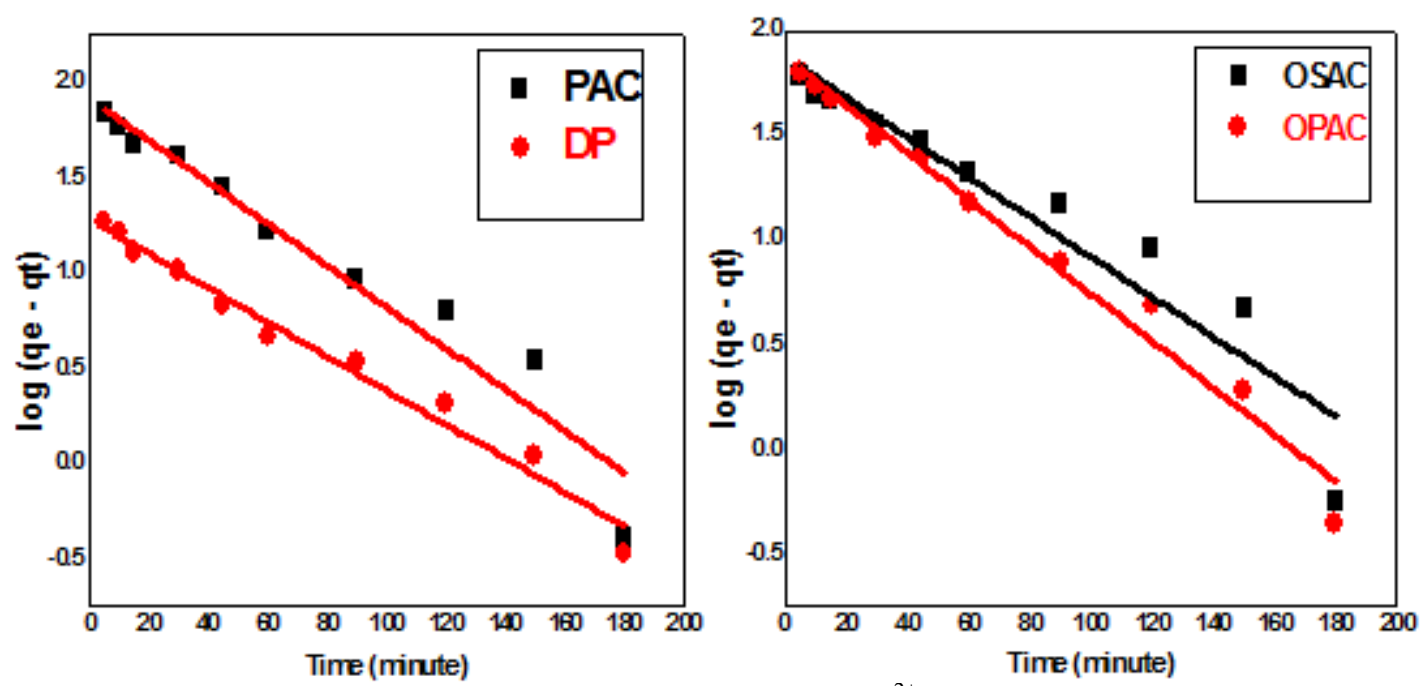

Figure 10: Pseudo-first-order model for the adsorption of $\mathrm{Hg}^{2+}$ by OSAC, OPAC, PAC and DP.

Table 4: Parameters of first - order kinetic model for adsorption of 500 ppm (OSAC, OPAC), 400 ppm (PAC) and 250 ppm (DP) $\mathrm{Hg}^{2+}$.

\begin{tabular}{|c|c|c|c|c|}
\hline \multirow{2}{*}{ Adsorbent Code } & \multicolumn{4}{|c|}{ Pseudo - first order } \\
\cline { 2 - 5 } & $\begin{array}{c}\mathrm{q}_{\mathrm{e}} \exp \\
\mathrm{mg} / \mathrm{g}\end{array}$ & $\begin{array}{c}\mathrm{q} \text { ecal } \\
\mathrm{mg} / \mathrm{g}\end{array}$ & $\mathrm{K}_{1}\left(\mathrm{~min}^{-1}\right)$ & 0.898 \\
\hline OSAC & 240.350 & 75.410 & 0.021 & 0.979 \\
\hline OPAC & 199.707 & 74.750 & 0.025 & 0.938 \\
\hline PAC & 115.146 & 82.940 & 0.025 & 0.977 \\
\hline DP & 75.532 & 19.309 & 0.020 & \\
\hline
\end{tabular}
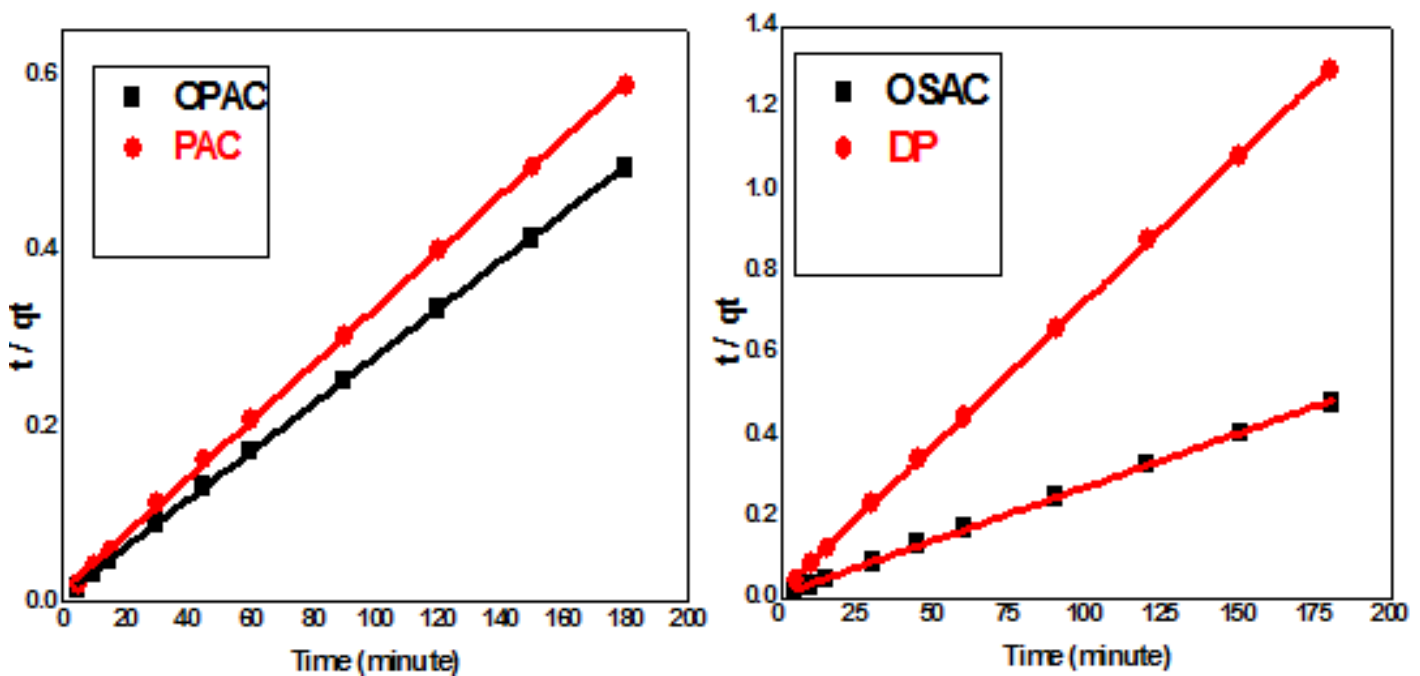

Figure 11: Pseudo-second-order kinetic model for the adsorption of $\mathrm{Hg}^{2+}$ by OSAC, OPAC, PAC and DP.

Volume 4 Issue 11, November 2015 


\section{International Journal of Science and Research (IJSR) \\ ISSN (Online): 2319-7064 \\ Index Copernicus Value (2013): 6.14 | Impact Factor (2014): 5.611}

Table 5: Parameters of second - order kinetic model for adsorption of $500 \mathrm{ppm}$ (OSAC, OPAC), $400 \mathrm{ppm}$ (PAC) and $250 \mathrm{ppm}(\mathrm{DP}) \mathrm{Hg}^{2+}$

\begin{tabular}{|c|c|c|c|c|}
\hline \multirow{2}{*}{$\begin{array}{c}\text { Adsorbent } \\
\text { Code }\end{array}$} & \multicolumn{4}{|c|}{ Pseudo - second order } \\
\cline { 2 - 5 } & $\begin{array}{c}\text { qeexp } \\
\mathrm{mg} / \mathrm{g}\end{array}$ & $\begin{array}{c}\text { qecal } \\
\mathrm{mg} / \mathrm{g}\end{array}$ & $\begin{array}{c}\mathrm{K}_{2}\left(\mathrm{~g} \cdot \mathrm{mol}^{-1}\right. \\
\left.\mathrm{min}^{-1}\right)\end{array}$ & $\mathrm{R}^{2}$ \\
\hline OSAC & 240.350 & 378.787 & 0.186 & 0.999 \\
\hline OPAC & 199.707 & 367.647 & 0.199 & 0.999 \\
\hline PAC & 115.146 & 310.559 & 0.143 & 0.999 \\
\hline DP & 75.532 & 140.252 & 0.274 & 0.999 \\
\hline
\end{tabular}

\section{Model of Intra Particle Diffusion}

The model of intra-particle diffusion was used in analysis kinetic results because it explains the mechanism of diffusion by Weber and Morris equation. The linear relation of intraparticle diffusion model was calculated as follows:
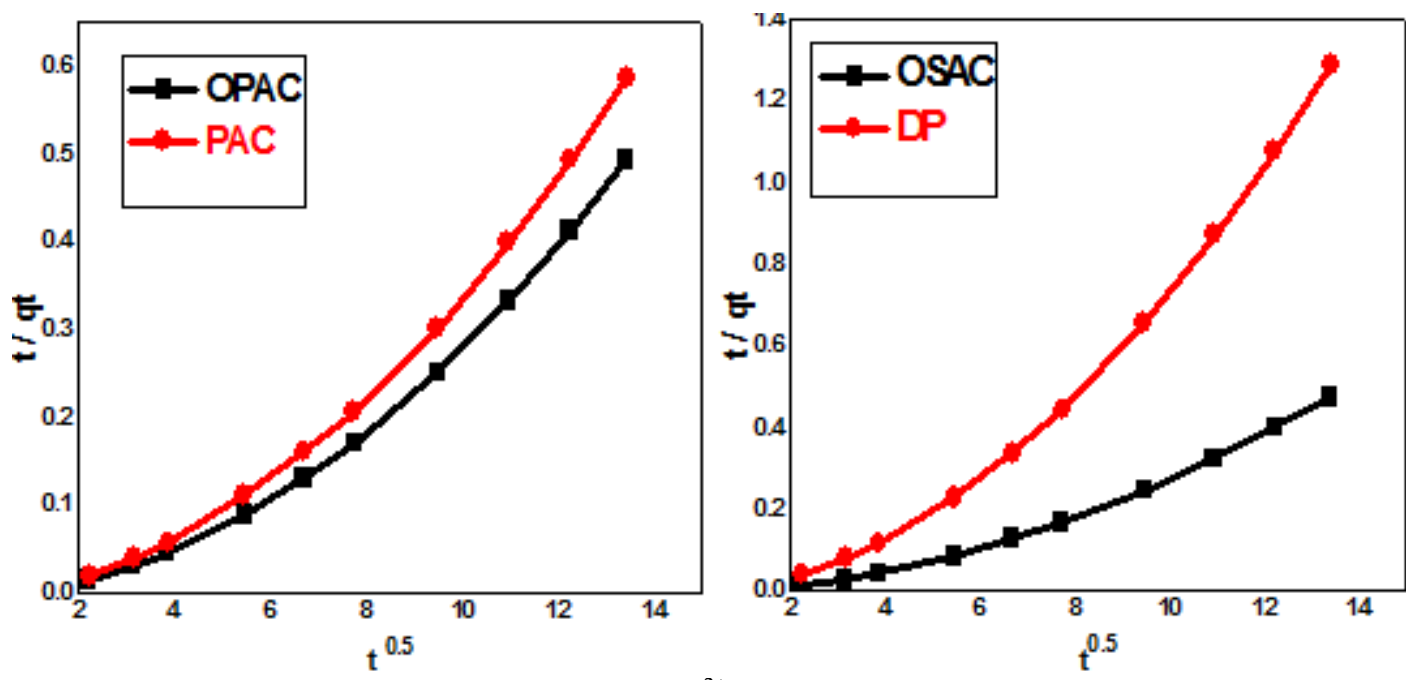

Figure 12: Intra-particle diffusionplots for adsorption of $\mathrm{Hg}^{2+}$ on 500 ppm (OSAC, OPAC), 400 ppm (PAC) and 250 ppm (DP).

Table 6: Intra-particle diffusion parameters for adsorption of $\mathrm{Hg}^{2+}$ by 500 ppm (OSAC, OPAC), 400 ppm (PAC) and 250 ppm (DP)

\begin{tabular}{|c|c|c|c|}
\hline \multicolumn{4}{|c|}{ Intra-particle diffusion model } \\
\hline Adsorbent code & $\mathrm{R}^{2}$ & $\mathrm{Kd}$ & Intercept \\
\hline OSAC & 0.966 & 0.041 & -0.116 \\
\hline OPAC & 0.963 & 0.042 & -0.120 \\
\hline PAC & 0.965 & 0.050 & -0.139 \\
\hline DP & 0.963 & 0.111 & -0.320 \\
\hline
\end{tabular}

\section{Thermodynamic Parameters Evaluation}

The dependence of adsorption's temperature, is connected to venous Thermodynamic parameters. To make a study on the adsorption's thermodynamics, Adsorption studies were done at 25,35 , and $45^{\circ} \mathrm{C}$. The standard free energy change, $\Delta \mathrm{G}^{\circ}$, was determined as follows:

$$
\Delta \mathbf{G}^{\mathbf{0}}=\Delta \mathbf{H}^{\mathbf{0}}+\mathbf{T} \Delta \mathbf{S}^{\mathbf{o}}
$$

The value of $\Delta \mathrm{H}^{\circ}$ and $\Delta \mathrm{S}^{\circ}$ were calculated from the Van't Hoff equation:

$$
\ln K_{d}=\frac{\Delta S^{\circ}}{R}-\frac{\Delta H^{\circ}}{R T}
$$

The plot of kd against $1 / \mathrm{T}$ appeared to be linear as shown in figure (13). $\Delta \mathrm{S}^{\mathrm{o}}$ and $\Delta \mathrm{H}^{\mathrm{o}}$ values were obtained from the intercept and slope of linear relation. Values of $\Delta \mathrm{S}^{\mathrm{o}}, \Delta \mathrm{H}^{\mathrm{o}}$, and

$$
\mathbf{q}_{\mathbf{t}}=\mathbf{K}_{\mathrm{d}} \mathbf{t}^{0.5}+\mathbf{C}
$$

Where $\mathrm{C}$ is the intercept and $\mathrm{Kdis}$ the rate constant of intra-particle diffusion ( $\mathrm{mg} g-{ }_{-}^{1} \min ^{-0.5}$ ). As stated by the model, curve of qtagainst $\mathrm{t}^{0.5}$ obey a linear relation if there is adsorption process involving intra-particle diffusion. If these lines came from the origin point, so the intra-particle diffusion was the rate controlling step. If there were no passing through the origin point, this is indicated that some degree of control from boundary layer and this extra indication that the intra-particle diffusion was not the individual rate preventive phase. $\mathrm{Kd}$ values were given in table (6). The curves did not come from origin point in this experiment figure (12) that showed that the intra particle diffusion was not the individual rate preventive phase.
$\Delta \mathrm{G}^{\mathrm{o}}$ were obtained from slope and intercept, correspondingly, of the curve of $\operatorname{lnKd}$ against $1 / \mathrm{T}$, as shown in figure (13). $\Delta \mathrm{S}^{\mathrm{o}}, \Delta \mathrm{H}^{\mathrm{o}}$, and $\Delta \mathrm{G}^{\mathrm{o}}$ were attained for the $\mathrm{Hg}$ (II) adsorption on OSAC, OPAC, PAC and DP are summarized in table (7). The change of enthalpy is related to the chemical connection; consequently, the positive enthalpy value of adsorption $\Delta \mathrm{H}^{\circ}$ attained in the present study approves the presence of adsorption endothermic process to be likely because of chemisorption and strong interactions between the efficient groups on the surface of the adsorbent and $\mathrm{Hg}$ (II) ions. The $\Delta \mathrm{S}^{\mathrm{o}}$ value is related to the adsorbed ions' ordering or geometry. The positive value of $\Delta \mathrm{S}^{\circ}$ proposes a higher rate in the disorder and randomness at the solid solution interface during the process of adsorption. The standard Gibbs free energy change $\left(\Delta G^{\circ}\right)$ is the essential criterion of spontaneity of an adsorption process. The negative values for $\Delta G^{o}$ indicate that the adsorption process is spontaneous and thermodynamically favorable. The high negative values of $\Delta \mathrm{G}^{\mathrm{o}}$ indicate a superior order of reaction and a stronger driving force the adsorption of $\mathrm{Hg}$ (II) on the surface of the adapted water hyacinth activated carbon and dried papyrus plant. 


\section{International Journal of Science and Research (IJSR) \\ ISSN (Online): 2319-7064}

Index Copernicus Value (2013): 6.14 | Impact Factor (2014): 5.611

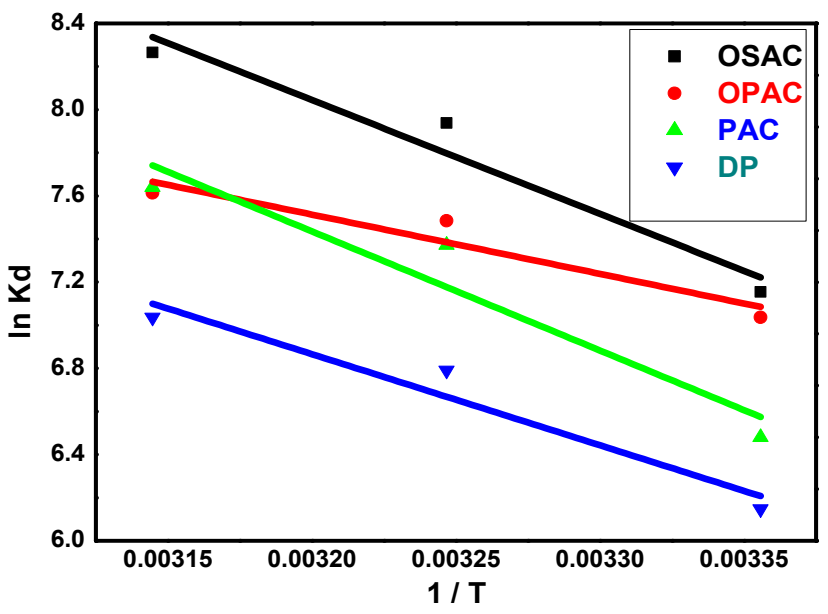

Figure 13: the plots of $\operatorname{lnKd}$ versus $1 / \mathrm{T}$ for estimations of thermodynamic parameters of the adsorption process of $\mathrm{Hg}^{2+}$ by OSAC, OPAC, PAC and DP. Condition : $\left(\mathrm{C}_{\mathrm{o}}=200 \mathrm{ppm}, \mathrm{T}=25\right.$ $-45^{\circ} \mathrm{C}, \mathrm{t}=5 \mathrm{~h}$, adsorbent dose $=0.025 \mathrm{~g} / 25 \mathrm{ml}$ ).

Table 7: Thermodynamic parameters for adsorption of $\mathrm{Hg}^{2+}$ by OSAC, OPAC, PAC and DP at different temperatures

\begin{tabular}{|c|c|c|c|c|c|c|}
\hline Adsorbents & $\begin{array}{c}\text { Mercury } \\
\text { Concentration } \\
(\mathrm{mg} / \mathrm{L})\end{array}$ & $\begin{array}{c}\Delta \mathrm{H}^{\mathrm{o}} \\
(\mathrm{KJ} / \mathrm{mol})\end{array}$ & $\begin{array}{c}\Delta \mathrm{S}^{\mathrm{o}} \\
(\mathrm{KJ} / \mathrm{mol})\end{array}$ & \multicolumn{3}{|c|}{$\Delta \mathrm{G}^{\mathrm{o}}(\mathrm{KJ} / \mathrm{mole})$} \\
\hline OSAC & 200 & 43.922 & 0.207 & -17.893 & -19.967 & -22.042 \\
\hline OPAC & 200 & 22.877 & 0.135 & -17.553 & -18.910 & -20.266 \\
\hline PAC & 200 & 45.958 & 0.208 & -16.289 & -18.378 & -20.467 \\
\hline DP & 200 & 35.158 & 0.169 & -15.379 & -17.075 & -18.771 \\
\hline
\end{tabular}

\section{Conclusion}

While using results, it is apparent the mercury removal values realized with $\mathrm{HNO}_{3}$ solution revised papyrus plant $\mathrm{AC}$ were being higher than those of dried papyrus plant due to the raise throughout the number of carboxylic group in the top of revised AC. The principle attributes of this particular removing course of action incorporate (i) convenience, (ii) charge success, (iii) rapidity and (iv) an increased removing effectiveness of harmful mercury ions. Based on your experimental outcomes of this particular analyze, these data could be attracted:

- The optimum removing effectiveness occurred in $\mathrm{pH}$ 5. 0 .

- This effectiveness of mercury removing elevated both equally with an increase of contact moment and original mercury attention

- The benefits showed that adsorption elevated speedily until eventually achieve on the balance moment ( 90 minute OSAC, OPAC, and PAC, and 60 minute DP).

- This experimental data were being nicely equipped with all the linear form of Langmuir model.

- Adsorption kinetics put into practice a pseudo-second-order model.

- Thermodynamic variables, which includes $\Delta \mathrm{H}^{\mathrm{o}}, \Delta \mathrm{G}^{\mathrm{o}}$, and $\Delta \mathrm{S}^{\mathrm{o}}$ for the means of mercury adsorption by aqueous answer on to dehydrated papyrus plant and revised papyrus plant $\mathrm{AC}$ suggested that adsorption will end up being endothermic and spontaneous practice.

\section{References}

[1] Clarkson, T.W.,. "Mercury: major issues in environmental health". EnvironHealth prospect. 100 (1992): p. 31-38.
[2] Berglund, F., Bertin, M., Chemical Fallout. Springfield, IL Thomas (1969).

[3] WHO, Environmental Health Criteria, Methylmercury, World Health Organization, Geneva, 101 (1990): p. 68-102.

[4] Baeyens, R., Ebinghous, R., Vasilev, O. (Eds.), "Global and Regional Mercury Cycles": Sources, Fluxes and Mass Balances. Kluwer Academic Publishers, 1996.

[5] Miretzky P, Cirelli AF. "Hg (II) removal from water by chitosan and chitosan derivatives": a review. Hazard Mater, 167 (2009): p. 10-23.

[6] N. Kannan and M. M. Sundaram, "Kinetics and mechanism of removal of methylene blue by adsorption on various carbons-a comparative study",Dyes and Pigments, 51 (2001): p. 25-40.

[7] A. Jumasiah, T. G. Chuah, J. Gimbon, T. S. Y. Choong, and I. Azni, "Adsorption of basic dye onto palm kernel shell activated carbon: sorption equilibrium and kinetics studies",Desalination,186 (2005): p. 57-64.

[8] D. Kavitha and C. Namasivayam, "Experimental and kinetic studies on methylene blue adsorption by coir pith carbon", Bio resource Technology, 98 (2007): p. $14-21$.

[9] V. K. Gupta, R. Jain, and S. Varshney, "Removal of React fix golden yellow 3 RFN from aqueous solution using wheat husk- An agricultural waste",Journal of Hazardous Materials, 142 (2007): p. 443-448.

[10] V. K. Gupta, A. Mittal, R. Jain, M. Mathur, and S. Sikarwar, "Adsorption of Safranin-T from wastewater using waste materials- activated carbon and activated rice husks", Journal ofColloid and Interface Science, 303 (2006): p. 80-86.

[11]Xiaoyan tan et al. , "Adsorption of $\mathrm{Pb}$ (11) on Activated Carbon Treated by Nitric Acid", Advantest Materials Research 550 (2012): p 2190 2193.

[12] C.-H. Shin, J.-S. Bae, "Performance of an activated carbon adsorbed in a water reclamation system with an electrolysis reactor", Journal of Industrial and Engineering Chemistry, 15 (2009): p. 179-184.

[13]P. Carrott, M. Carrott, J. Nabais, "Influence of surface ionization on the adsorption of aqueous mercury chloro complexes by activated carbons", Carbon, 36 (1998): p. 11-170

[14]D. Sahoo, R. Kar, R. Das, "Bioaccumulation of heavy metal ions by Bacillus circulars", Bio resource technology, 41 (1992): p. 177-179.

[15]R. Gong, Y. Ding, H. Liu, Q. Chen, Z. Liu, "Lead bio-sorption and desorption by intact and pretreated spirulina maxima biomass", Chemosphere, 58 (2005): p. 125-130.

[16]F. Boudrahem, F. Aissani- Benissad, H. Ait-Amar, "Batch sorption dynamics and equilibrium for the removal of lead ions from aqueous phase using activated carbon developed from coffee residue activated with zinc chloride", Journal of environmental management, 90 (2009): p. 30313039 .

\section{Volume 4 Issue 11, November 2015}

